\section{CARTA AO EDITOR}

\section{RISCO DE DESENVOLVER CÂNCER EM RECEPTORES DE SANGUE VIOLETADO. VALIDADE DA ENTREVISTA}

\section{Senhor Editor:}

Em exemplar contendo resumos dos trabalhos apresentados na VI Reunião Anual de Pesquisa Aplicada em Doença de Chagas (volume 22, suplemento II, 1989) deparamo-nos com estudo de autoria de Souza, DO, Carneiro SS, Galvão PM, Irusta, RC, Cardoso VM e Luquetti, AO sobre "Risco de desenvolver câncer em receptores de sangue violetado. Validade da entrevista". Al apresentam dados preliminares citando que em hospital de Goiás, que atende enfermos de câncer, indagam a receptores de transfusões, entre pacientes já triados por esta variável afinal são pacientes que procuraram um Serviço que cuida de pessoas com tumores - se o sangue que tinham recebido alguma vez estava roxo ou não. Foram encontrados 37 , em 4.765 , que se lembravam da administração de sangue nessa condição; destes, em 26 foi possivel, por consulta a prontuário, definir histologicamente a lesão, obtendo-se 18 benignas e oito malignas. $O$ texto não cita, comparativamente, o número de lesões neoplásicas em doentes que não tomaram sangue violetado e tal informe é crucial para qualquer conclusão. Do ponto de vista estatístico, este tipo de pesquisa restrospectiva, que não tem checagem documental e confia exclusivamente na memória do enfermo, mediante realização em hospital de uma "Associação de Combate ao Câncer", com evidente "bias" no sentido de recuperar gente com neoplasia, é dificil de avaliar. Ainda mais, problemática torna-se a investigaçào quando é sabido que individuos com estoques superiores de ferro no corpo estão a risco de maior quantidade de neoplasias 567 , sendo que um dos métodos de aumentar as reservas de ferro no organismo é certamente a transfusão. Transfusões sanguíneas aumentam o perigo de recorrências de alguns tumores, provavelmente por efeito imunodepressor 1234 , sem esquecer a questão inicial critica, ou seja, que doentes que recebem transfusões têm motivo para tal, um dos quais pode ser relacionado com neopiasia. Entendemos que o comunicado corresponda a algo em andamento, com divulgação de elementos prévios, mas consideramos extraordinariamente dificil organizar grupo controle, pareado por todos os fatores de risco para neoplasia; tambem teriamos muito receio de executar um plano de porte do que deverá ser necessário para detectar evidência do carcinogênese, com base em dado tão "soft" como a entrevista, a menos que seja viável corroborá-la, comparando-se o registro mais documental, com a informação do Banco, de que o sangue foi ou não violetado. De outro lado, este tipo de informação, ainda não claramente definida, pode levar a mais uma das decisões que perturbam o ambiente médico, especialmente se isto for divulgado pela imprensa leiga, prejudicando um método definitivamente eficaz e incorporado ao controle da doença de Chagas, em nosso meio. Sugeririamos aos colegas uma análise prospectiva, com alocação randomizada, ou pelo menos pareação randomizada, de pacientes, entre sangues violetados e não violetados, permitindo estatisticamente, maior precisão para definir, sem dúvida, se a violeta de genciana envolve ou não ação cancerigena.

\section{REFERÊNCIAS BIBLIOGRÁFICAS}

1. Blumberg N, Heal JM, Murphy P, Agarwal MM, Chuang C. Association between transfusions of whole blood and recurrense of cancer. British Medical Journal 293:530-533, 1986.

2. Gascon P, Zoumbs NC, Young Ns. Immunologic abnormalities in patients receiving multiple blood transfusions. Annals of Internal Medicine 100:173-177, 1984.

3. Hamblin T. Blood transfusions and cancer: anomalies explained? British Medical Journal 293:51 7-518, 1986.

4. Kaplan BJ, Sarnaik S, Gitlin J, Lusher J. Diminished helper/supressor lymphocyte rations and natural killer activity in recipients of repeated blood transfusion. Blood The Journal of the American Society of Hematology 64:308-310, 1984.

5. Selby JV, Friedman GD. Epidemiologic evidence of an association between body iron stores and risk of cancer. International Journal of Cancer 41:677-682, 1988.

6. Stevens R, Jones Y, Micozzi M, Taylor PR. Body iron stores and the risk of cancer. The New England Journal of Medicine 319:1047-1052, 1988.

7. Stevens RG, Beasley RP, Blumberg BS. Iron binding proteins and risk of cancer in Taiwan. Journal of the National Cancer Institute 76:605-610, 1986.

\section{Prof. Vicente Amato Neto \\ Dr. Jacyr Pasternak \\ Universidade de São Paulo}

